\title{
Research of General Deduction Optimization on PEMFC Manufacturing with Fuzzy Linguistic Analysis
}

\author{
Tian-Syung Lan, Han-Chen Huang, and Cheng-I Hou \\ Yu Da University of Science and Technology, Miaoli 36143, Taiwan \\ Correspondence should be addressed to Han-Chen Huang; hchuang@ydu.edu.tw
}

Received 29 October 2013; Accepted 4 December 2013; Published 12 January 2014

Academic Editor: Massimo Scalia

Copyright (C) 2014 Tian-Syung Lan et al. This is an open access article distributed under the Creative Commons Attribution License, which permits unrestricted use, distribution, and reproduction in any medium, provided the original work is properly cited.

\begin{abstract}
In control questions, multiquality parameters are the most suitable, as they are everlasting in highly complex misalignment relations; the relationship between the parameter and quality of mutual influence is complex, and often massive redundant operations must be achievable by the test installation. Because the most suitable multiquality parameter is difficult to achieve, this study designates the proton exchange membrane fuel cell as the topic, takes the inlet temperature, inlet pressure, and incoming flow speed as the controlling elements, uses conformity fuzzy meaning analysis and the ideal solution similar order by chance law (TOPSIS), and discusses the parameters to control the influences of the quality goal. As outlet temperature, outlet pressure, pressure drop do not operate after the experiment, this study uses the meaning deduction method and develops a set of the most suitable control mechanisms. The research results show that this study develops a quality decision scheme for a set of meanings by using the misalignment and a high order complexity question. It also penetrates the meaning method, which guarantees that the quality and experimental efficiency may elevate the competitive power of science and technological undertakings development, effectively economize costs, and provide a set of economies and perspectives. The multiqualities are the most suitable control plan which meets the demands of practice.
\end{abstract}

\section{Introduction and Research Purpose}

Fuel cells mainly use hydrogen and oxygen. Hydrogen is high in density, has low pollution, and is easily obtained; hence, the development of hydrogen-based energy technology is very favorable. Moreover, power generation by electrochemical reaction without a warm-up process has higher specific heat efficiency in energy conversion. The products of an electrochemical reaction are pure, which meets the current environmental trend. Thus, fuel cell is green energy technology with great potential.

Proton exchange membrane fuel cells (PEMFCs) require consideration of many operating conditions, such as temperature, pressure, reaction gas concentration, and flow rate. In order to meet requirements, users often rely on experience or reference manuals to determine the operating parameters, or even use the trial-and-error method to test the experimental table. Hence, subjective judgment often shortens service life or damages the Proton exchange membrane, which wastes many working hours and increases costs. There are many operating conditions of the PEMFC [1-3], and the general controllable factors include temperature, pressure, flow rate, reaction gas concentration, and battery type selection. As the interactive effects between factors are complex, differences between quality objectives may result. To address the PEMFC's multiquality characteristics problem, most previous studies [4-6] used one-factor-at-a-time experiment. Although this method can simplify the multiquality operation process, in actual operation, the parameters have different effects on quality and may not be able to fully meet the needs in practice. Therefore, it is necessary to explore how to provide comparative analysis of various control factors, as well as quality.

The multiquality parameter optimization problem often involves highly complex nonlinear relationships. In practice, the parameters are determined upon the operator's experience; hence, the result may not be optimal and cannot guarantee multiquality objective optimization or comparison. Most parameter optimization studies only consider a single quality objective; otherwise, the cost is too high if all requirements 

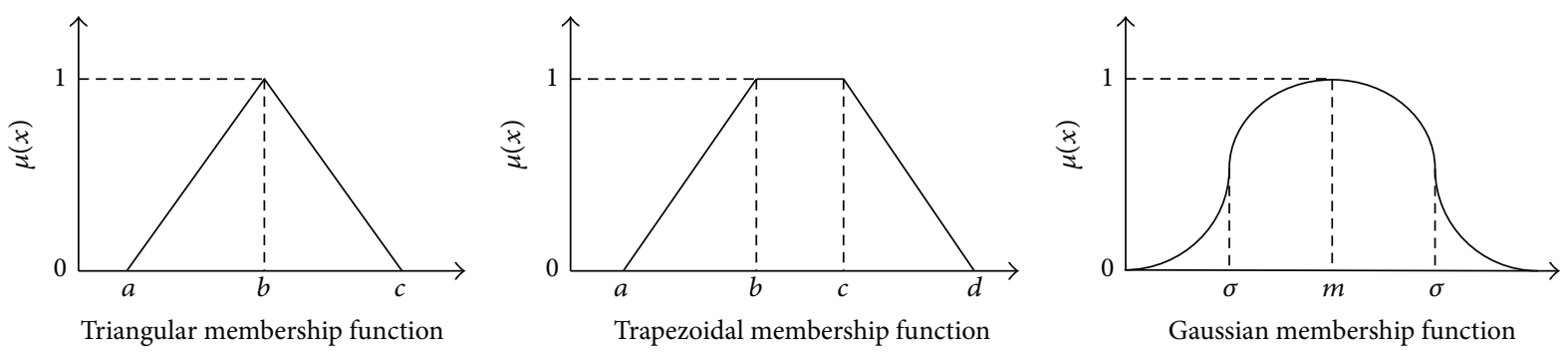

Figure 1: Membership functions.

are met. Among multiquality parameter optimization studies, most are optimization programs under specific conditions, which can only be achieved through the operation of processing equipment. Hence, it is an important issue to develop an optimization mechanism, without the need of equipment operation, but by inference.

This study chose inlet temperature, inlet pressure, and flow rate as control factors for PEMFC to explore the impact of parameter control on outlet temperature, outlet pressure, pressure drop, and other quality objectives. According to the experimental requirements and without the need of equipment operation, this study employed semantic inference analysis to determine the optimum operating parameters and obtain the optimum quality objectives, in order to effectively reduce the cost of experiments and develop the fuzzy optimization mechanism for multiquality PEMFC.

\section{Research Method}

2.1. Fuel Cell Parameters and Quality Identification. For the current PEMFC, the issue of flow parameter optimization is very important. Different control parameters lead to different results, have a direct impact on fuel cell efficiency, and even damage the proton exchange membrane in some cases. As there are too many parameters to be fully considered in this study, upon literature review, this paper only discusses the optimal quality characteristics of PEMFC, including channel outlet temperature, outlet pressure, and pressure drop. According to the preliminary qualitative analysis results of various parameters against various quality objectives, this study selected inlet temperature, inlet pressure, and flow rate, as the flow parameters of PEMFC. The fuzzy theory was applied in the measurement of multiquality objectives.

2.2. Fuzzy Theory. The fuzzy theory was proposed by Professor Zadeh of UC Berkeley in 1965. It is a fuzzy concept of quantitative knowledge used mainly for processing fuzzy messages or incomplete information in the human brain. It can make correct judgments without precise complicated calculation processes. All areas of knowledge can be fuzzy, and can be understood only by fuzzification and extension of conventional clear sets to the fuzzy set. The advantage of fuzzification is that it can provide greater extension and fault tolerance resistance and, therefore, it is more suitable for application in the nonlinear systems of the real world.
All functions with values in the interval of $[0,1]$ can be membership functions, and common membership functions include Triangular membership function, Trapezoidal membership function, and Gaussian membership function (Figure 1).

The main purpose of defuzzification is to obtain the definite values of the fuzzy set in order to facilitate computation, where the computation process is known as defuzzification. Common defuzzification methods include the following.

(1) Center of Gravity Method. The center of gravity method is to obtain the position of the same center of gravidity and obtain the central value of the fuzzy set that represents the entire set. If fuzzy set $A$ membership function is $\mu_{\widetilde{A}}(x)$, then $x_{i}$ is a variable value, and the position of the center of gravity of the function diagram is

$$
F\left(x_{i}\right)=\frac{\sum_{i} x_{i} * \mu_{\widetilde{A}}\left(x_{i}\right)}{\sum_{i} \mu_{\widetilde{A}}\left(x_{i}\right)} .
$$

(2) Center of Area Method. If $x_{i}$ is a variable value, then the position of the center of gravity of the function diagram is

$$
F\left(x_{i}\right)=\frac{\sum\left[\sum_{x_{i}} * \mu_{\widetilde{A}}\left(x_{i}\right)\right] * x_{i}}{\sum\left[\sum_{\mu_{\widetilde{A}}}\left(x_{i}\right)\right]} .
$$

2.3. Definition of Fuzzy Semantic Rules. The fuzzy semantic rules [7] are the key step of the entire operation process, which may affect the accuracy of the answer. By using planned parameter combinations, according to the IF-THEN rule, this paper establishes nine groups of fuzzy rules for the objectives and control factors. The rules are established based on the fuzzy relationship between the control factor (Input) and objective (Output). By computation of the Cartesian product equation, the intersection of the membership grade of the input object and output object [8] is

$$
R=\text { Input } * \text { Output, }
$$

where $R$ is the fuzzy relationship between the control factor and objective; Input is control factor; Output is objective characteristics; $*$ is Cartesian product.

The fuzzy relationship of the rules is integrated by OR, which indicates the maximum membership grade of two fuzzy relationships, namely, the union of the two sets, represented as Rule $1+$ Rule 2 , and the result is $\mu \mathrm{R} 1+\mu \mathrm{R} 2=$ 
TABLE 1: Standard orthogonal array.

\begin{tabular}{|c|c|c|c|c|c|c|}
\hline \multirow{2}{*}{ Orthogonal array } & \multirow{2}{*}{ Number of columns } & \multirow{2}{*}{ Maximum number of factors } & \multicolumn{4}{|c|}{ Maximum row values at these levels } \\
\hline & & & 2 & 3 & 4 & 5 \\
\hline$L_{4}$ & 4 & 3 & 3 & - & - & - \\
\hline$L_{8}$ & 8 & 7 & 7 & - & - & - \\
\hline$L_{9}$ & 9 & 4 & - & 4 & - & - \\
\hline$L_{12}$ & 12 & 11 & 11 & - & - & - \\
\hline$L_{16}$ & 16 & 15 & 15 & - & - & - \\
\hline$L_{16}$ & 16 & 5 & - & - & 5 & - \\
\hline$L_{18}$ & 18 & 8 & 1 & 7 & - & - \\
\hline$L_{25}$ & 25 & 6 & - & - & - & 6 \\
\hline$L_{27}$ & 27 & 13 & - & 13 & - & - \\
\hline$L_{32}$ & 32 & 31 & 31 & - & - & - \\
\hline$L_{32}$ & 32 & 10 & 1 & - & 9 & - \\
\hline$L_{36}$ & 36 & 23 & 11 & 12 & - & - \\
\hline$L_{36}$ & 36 & 16 & 3 & 13 & - & - \\
\hline$L_{50}$ & 50 & 12 & 1 & - & - & - \\
\hline$L_{54}$ & 54 & 26 & 1 & 25 & - & 11 \\
\hline$L_{64}$ & 64 & 63 & 63 & - & - & - \\
\hline$L_{64}$ & 64 & 21 & - & - & 21 & - \\
\hline$L_{81}$ & 81 & 40 & - & 40 & - & - \\
\hline
\end{tabular}

$\max \{\mu \mathrm{R} 1, \mu \mathrm{R} 2\}$. It obtains the maximum membership grade by comparing the membership grade values of the fuzzy semantic relationships of the rules.

Based on literature review, this paper uses the triangular fuzzy membership function to divide the objectives into intervals. More intervals suggest higher accuracy of the answer. The center of gravity method is used for defuzzification, then applied in the semantic rules for multiquality objectives, and is converted into a definite value for the operation of technique for order preference by similarity to ideal solution (TOPSIS) integrated with multiquality characteristics. The differences in the results of the two graphic definitions are compared to confirm the accuracy and applicability of fuzzy quantification.

2.4. Taguchi Method Planning. The Taguchi method is an experimental research method for quality improvement. Through practical operations or computer simulation, it determines design parameters and aims to produce high quality at the lowest cost and in the shortest time. The purpose of the orthogonal array is to determine the optimal design parameters and standards with fewer experiments to reach the desired goal [9]. The main advantage and feature of the Taguchi method is that it uses the telecommunication output signal and noise ratio $(S N)$ as the quality index. The greater the $S N$ is, the better the communication quality is [10]. The Taguchi method lists 18 standard orthogonal arrays (Table 1). To directly use the standard orthogonal array, the number of levels of the desired research factors should be consistent with the levels of the rows of the orthogonal array. Meanwhile, the smallest orthogonal array that meets the requirements should be used to save the cost of experiments.
The quality characteristic is of the smaller-the-better and the $S N$ ratio is defined as

$$
\frac{S}{N}=-10\left(\log \sum_{i=1}^{n} \frac{y_{i}^{2}}{n}\right) \mathrm{dB},
$$

where $n$ is the number of tests in each group of experiments. When the quality characteristic is of the larger-the-better, $1 / y$ is used for computation; then,

$$
\frac{S}{N}=-10\left(\log \sum_{i=1}^{n} \frac{1 / y_{i}^{2}}{n}\right) \mathrm{dB} .
$$

To meet the requirements of actual optimization, this paper uses inlet temperature, inlet pressure, and flow rate as the control factors and determines the level scope (low, medium, and high). According to the $L_{9}\left(3^{4}\right)$ orthogonal array, semantic planning and simulation experiments are conducted to explore the impact of flow parameters on outlet temperature, outlet pressure, pressure drop, and other quality objectives. Meanwhile, the optimal multiquality flow parameters of PEMFC are confirmed by inference.

2.5. TOPSIS. Another evaluation method for multiattribute decision making developed by using the concept of compromise solution is TOPSIS. The selected compromised solution should satisfy the condition that the distance from the positive ideal solution is the shortest and the distance from the negative ideal solution is the longest. By establishing the matrix operation, the compromise solution concept may be applied to establish the mathematical planning model for multiquality decision making. In the study of the TOPSIS method integrated with multiquality characteristics, the 


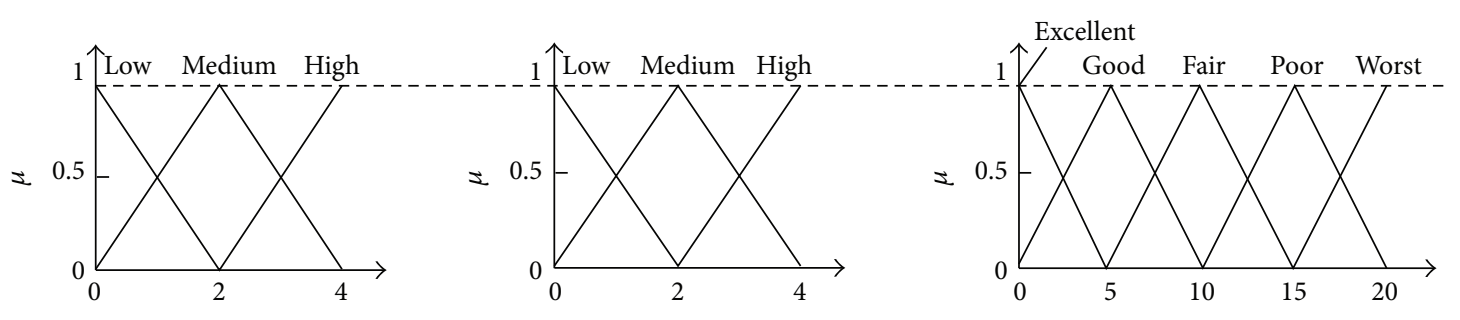

Figure 2: Relationship of membership functions.

experimental combinations of the orthogonal array are used as various programs, while the quality characteristics are used as the attributes before applying fuzzy multiattribute decision-making to convert the $S N$ ratios of the quality characteristics into values of TOPSIS in order to determine the optimal parameter combinations accordingly.

Using IC manufacturing as an example, Zhang [11] applied the gray multiattribute method to solve the multiquality characteristic problem of the Taguchi method. Moreover, the grey correlation method and the traditional Taguchi method were applied to process multiquality characteristic problems for comparison. The results suggested that the Taguchi method integrated with grey correlation is better than the conventional Taguchi method. Zhan [12] used the chemical experiment of the preparation of an S-CHBE optically active intermediate as an example, calculated the quality loss of a dynamic system based on the loss function in the Taguchi method, and processed the multiquality characteristic optimization by TOPSIS. Using plasma arc welding as an example, Hsu [8] combined grey relational analysis and the Taguchi method to solve multiquality characteristic problems. Based on the Taguchi method orthogonal array experiment, Wang [13] introduced grey relational analysis combined with TOPSIS for the continuous multiquality characteristics of static and dynamic systems, when measuring the optimal solution, the positive ideal solution, and the negative ideal solution. A quality improvement process analytical procedure was thus developed. In 2000, Fang [14] proposed a parameter selection method for processing multiquality characteristics by integrating the fuzzy theory, orthogonal array, and regression analysis. A factor level selection method was thus developed to solve the possible conflicts of factor level selection of quality characteristics. Although the research findings had very good reproducibility, the mean values and variances of the quality characteristic parameter combinations might differ when obtaining objective theoretical weights. Thus, it resulted in a long calculation process. Moreover, whether the results met the practical needs of business remained debatable.

As mentioned above, integrating more multiquality characteristics can be solved by the method of TOPSIS. Although TOPSIS can effectively obtain the optimal parameter combination using simple and easy to understand operational steps, whether the sorting results after integration meet the practical needs remains to be confirmed. Hence, it is necessary to study the use of the multicriterion decisionmaking method to solve multiquality characteristic problems for comparison and result confirmation. This preliminary analysis can provide considerable value on the use of TOPSIS in solving multiquality characteristic problems.

\section{Experimental Results and Discussion}

3.1. Multiquality Analysis. In this paper, the three parameter levels are selected based on the Taguchi experimental method; therefore, each triangle membership function is related to the peak point of its fuzzy area. Considering four input and twenty output intervals, the defuzzification of five linguistic grades using center of gravity can then be completed. Since two major parameters are considered for each attribute, the input (parameter) membership functions are regarded as the intersection of two fuzzy sets, and the height of fuzzy set is considered as Figure 2. The degree of membership for input (parameter) and output (attribute) can be described. Utilizing the average value of the fuzzy set to represent the entire set, we then have the quantified result for the fuzzy item of five linguistic grades.

This study applied the triangle membership function in the establishment of inference rules and the center of gravity method to obtain quality quantification characteristics. According to the Taguchi method parameter levels (low, medium, and high), this study arranged the quality characteristics corresponding to the parameter levels and established the configuration of the semantic experiment of $L_{9}\left(3^{4}\right)$ based on the inference fuzzy rule quality, as shown in Table 2. By applying the TOPSIS analytical process in the three semantic quality characteristics, the priority sequence values were obtained, as shown in Table 3. The computational steps of TOPSIS can be expressed as follows.

Step 1. This step involves a matrix based on all the information available that describes material's attributes and is called a "decision matrix". Each row of this matrix is allocated to one alternative and each column to one attribute. The decision matrix can be stated as

$$
D=\begin{gathered}
X_{1} \\
A_{1} \\
A_{2} \\
\cdot \\
A_{i} \\
\cdot \\
A_{m}
\end{gathered}\left[\begin{array}{ccccc}
x_{11} & x_{12} & \cdot & x_{1 j} & x_{1 n} \\
x_{21} & x_{22} & \cdot & x_{2 j} & x_{2 n} \\
\cdot & \cdot & \cdot & \cdot & \cdot \\
x_{i 1} & x_{i 2} & \cdot & x_{i j} & \cdot \\
\cdot & \cdot & \cdot & \cdot & \cdot \\
x_{m 1} & x_{m 2} & \cdot & x_{m j} & x_{m n}
\end{array}\right],
$$


TABLE 2: Multi-quality semantic experiment configuration.

\begin{tabular}{|c|c|c|c|c|c|c|}
\hline Rule & Inlet temperature & Inlet pressure & Flow rate & $\begin{array}{c}\text { Temperature } \\
\text { inference } \\
\text { characteristic }\end{array}$ & $\begin{array}{c}\text { Pressure } \\
\text { inference } \\
\text { characteristic }\end{array}$ & $\begin{array}{l}\text { Pressure drop } \\
\text { inference } \\
\text { characteristic }\end{array}$ \\
\hline 1 & Low & Low & Low & 1.33 & 10 & 1.33 \\
\hline 2 & Low & Medium & Medium & 1.33 & 10 & 10 \\
\hline 3 & Low & High & High & 5 & 10 & 18.67 \\
\hline 4 & Medium & Low & Medium & 10 & 5 & 5 \\
\hline 5 & Medium & Medium & High & 10 & 5 & 15 \\
\hline 6 & Medium & High & Low & 10 & 18.67 & 10 \\
\hline 7 & High & Low & High & 15 & 1.33 & 10 \\
\hline 8 & High & Medium & Low & 18.67 & 15 & 5 \\
\hline 9 & High & High & Medium & 18.67 & 15 & 15 \\
\hline
\end{tabular}

TABLE 3: Multi-quality semantic experiment integration.

\begin{tabular}{|c|c|c|c|c|c|}
\hline Rule & Inlet temperature & Inlet pressure & Flow rate & Priority sequence value & Ranking \\
\hline 1 & Low & Low & Low & 0.2534 & 9 \\
\hline 2 & Low & Medium & Medium & 0.3724 & 7 \\
\hline 3 & Low & High & High & 0.5563 & 4 \\
\hline 4 & Medium & Low & Medium & 0.3178 & 8 \\
\hline 5 & Medium & Medium & High & 0.5000 & 5 \\
\hline 6 & Medium & High & Low & 0.6372 & 2 \\
\hline 7 & High & Low & High & 0.4437 & 6 \\
\hline 8 & High & Medium & Low & 0.6067 & 3 \\
\hline 9 & High & High & Medium & 0.8309 & 1 \\
\hline
\end{tabular}

where $A_{i}$ represents the possible alternatives, $i=1,2$, $\ldots, m ; X_{j}$ denotes the attributes relating to alternative performance, $j=1,2, \ldots, n$; and $x_{i j}$ is the performance of $A_{i}$ with respect to attribute $X_{j}$.

Step 2. Obtain the normalized decision matrix $r_{i j}$. This can be represented as

$$
r_{i j}=\frac{x_{i j}}{\sqrt{\sum_{i=1}^{m} x_{i j}^{2}}}
$$

where $r_{i j}$ represents the normalized performance of $A_{i}$ with respect to attribute $X_{j}$.

Step 3. Assume that the weight of each attribute is $\left\{w_{j} \mid j=\right.$ $1,2, \ldots, n\}$ and the weighted normalized decision matrix $V=$ $\left[v_{i j}\right]$ can be found as

$$
V=w_{j} \cdot r_{i j}
$$

Here, $\sum_{j=1}^{n} w_{j}=1$.

Step 4. Develop the "ideal" (best) and "negative ideal" (worst) solutions in this step. The ideal and negative ideal solution can be expressed as

$$
\begin{aligned}
A^{+} & =\left\{\left(\max _{i} v_{i j} \mid j \in J\right),\left(\min _{i} v_{i j}\left|j \in J^{\prime}\right| i=1,2, \ldots, m\right)\right\} \\
& =\left\{v_{1}^{+}, v_{2}^{+}, \ldots, v_{j}^{+}, \ldots, v_{n}^{+}\right\},
\end{aligned}
$$

$$
\begin{aligned}
A^{-} & =\left\{\left(\min _{i} v_{i j} \mid j \in J\right),\left(\max _{i} v_{i j}\left|j \in J^{\prime}\right| i=1,2, \ldots, m\right)\right\} \\
& =\left\{v_{1}^{-}, v_{2}^{-}, \ldots, v_{j}^{-}, \ldots, v_{n}^{-}\right\},
\end{aligned}
$$

where $J=\{j=1,2, \ldots, n \mid j\}$ is associated with the beneficial attributes and $J^{\prime}=\{j=1,2, \ldots, n \mid j\}$ is associated with nonbeneficial attributes.

Step 5. Determine the distance measures. The separation of each alternative from the ideal one is given by $n$-dimensional Euclidean distance from the following equations:

$$
\begin{aligned}
& S_{i}^{+}=\sqrt{\sum_{j=1}^{n}\left(v_{i j}-v_{j}^{+}\right)^{2}}, \quad i=1,2, \ldots, m, \\
& S_{i}^{-}=\sqrt{\sum_{j=1}^{n}\left(v_{i j}-v_{j}^{+}\right)^{2}}, \quad i=1,2, \ldots, m .
\end{aligned}
$$

Step 6. The proximity of a particular alternative to the ideal solution is expressed in this step as follows:

$$
C_{i}^{+}=\frac{S_{i}^{-}}{S_{i}^{+}+S_{i}^{-}}, \quad i=1,2, \ldots, m ; 0 \leq C_{i}^{+} \leq 1 .
$$

Step 7. A set of alternatives is made in descending order according to the preference value indicating the most preferred and least preferred feasible solutions. 

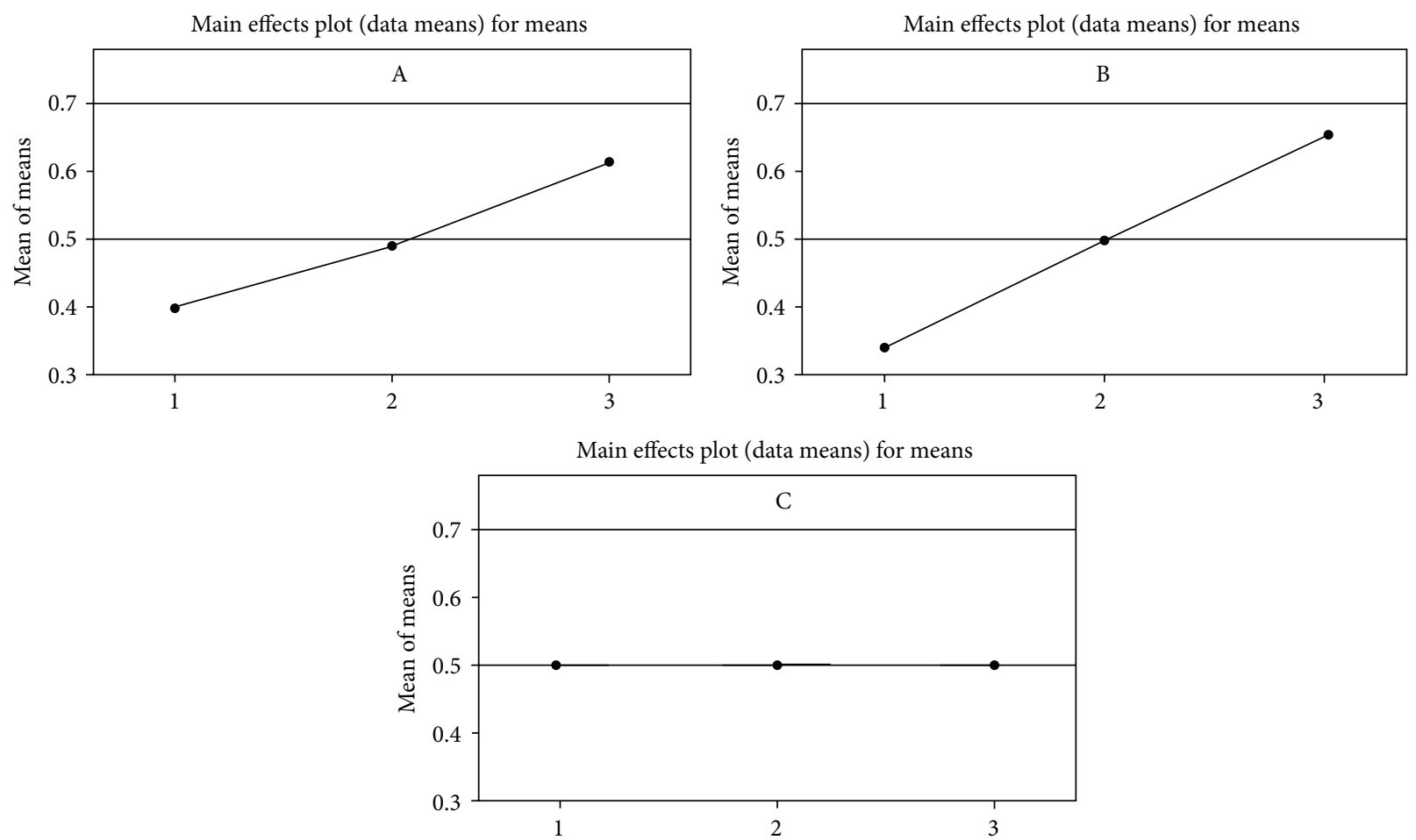

Figure 3: Three-quality semantic experimental response table.

TABLE 4: Three-quality semantic experimental response table.

\begin{tabular}{lccc}
\hline LEVEL & $\mathrm{A}$ & $\mathrm{B}$ & $\mathrm{C}$ \\
\hline 1 & 0.394 & 0.3383 & 0.4991 \\
2 & 0.485 & 0.493 & 0.507 \\
3 & 0.6271 & 0.6748 & 0.5 \\
DELTA & 0.2331 & 0.3365 & 0.0079 \\
RANK & 2 & 1 & 3 \\
\hline
\end{tabular}

3.2. Optimization Analysis Results of the Multiquality Semantic Experiment. This study applied the Taguchi method analysis of mean (ANOM) to select the larger-the-better characteristics of the sequence values, where the optimal semantic parameter combination is A3 B3 C2. Table 4 is three-quality semantic experiment response table. The optimal semantic parameter combination can also be obtained by the response table of the three-quality semantic experiment, as shown in Figure 3.

3.3. Multiquality Simulation Experiment. According to the COMSOL simulation experimental data, the full combination of parameters from the three levels is simulated by COMSOL. For quality characteristic data, TOPSIS was applied in the analysis of the TOPSIS priority value, as well as the integration of the multiquality. With the machined results based on the orthogonal array, the preference value for each experiment combination by using TOPSIS can then be achieved in Tables 5 and 6 .
3.4. Multiquality Simulation Experiment Optimization Analysis Results. The Taguchi method ANOM (analysis of mean) was used to obtain the response table and the simulation optimal parameter combination, according to the larger-thebest priority sequence value, which is A3 B3 C3, as shown in Table 7.

3.5. Multiquality Result Comparison. According to the proposed triangular fuzzy inference rules, the quality fuzzy quantification parameters were arranged by parameter levels. TOPSIS was applied to integrate multiquality attributes and compare the optimal parameter quality of the simulation research results. By the combination of A2 B2 C2 of the 27 groups of simulated data as the benchmark, this study compared and summarized the simulation experiment results, as shown in Table 8.

The optimal semantic combination of A3 B3 C2 was compared with the benchmark. The results showed that it is superior to the benchmark parameter by $14.29 \%$ in temperature, is superior to the benchmark parameter by $44.9 \%$ in pressure, and is superior to the benchmark parameter by $0.02 \%$ in pressure drop. Regarding simulation experiment comparison, the combination of A3 B3 C3 ranks first, is superior to the benchmark parameter by $14.29 \%$ in temperature, is superior to the benchmark parameter by $40.13 \%$ in pressure, and is superior to the benchmark parameter by $39.4 \%$ in pressure. Therefore, quality is superior to the semantic experiment combination. 
TABLE 5: Three-quality simulation experimental priority table.

\begin{tabular}{|c|c|c|c|c|c|c|c|c|}
\hline Rule & $\begin{array}{c}\text { Inlet } \\
\text { temperature }\end{array}$ & $\begin{array}{c}\text { Inlet } \\
\text { pressure }\end{array}$ & $\begin{array}{l}\text { Flow } \\
\text { rate }\end{array}$ & $\begin{array}{c}\text { Temperature } \\
\text { inference } \\
\text { characteristic }\end{array}$ & $\begin{array}{c}\text { Pressure } \\
\text { inference } \\
\text { characteristic }\end{array}$ & $\begin{array}{l}\text { Pressure drop } \\
\text { inference } \\
\text { characteristic }\end{array}$ & $\begin{array}{c}\text { Priority } \\
\text { sequence } \\
\text { value }\end{array}$ & Ranking \\
\hline 1 & Level 1 & Level 1 & Level 1 & 49.98598 & 0.722437 & 0.277563 & 0.110050211 & 27 \\
\hline 2 & Level 1 & Level 1 & Level 2 & 49.98657 & 0.454011 & 0.545989 & 0.217650744 & 24 \\
\hline 3 & Level 1 & Level 1 & Level 3 & 49.98748 & 0.099154 & 0.900846 & 0.381089861 & 21 \\
\hline 4 & Level 1 & Level 2 & Level 1 & 49.98762 & 2.722464 & 0.277536 & 0.417416162 & 18 \\
\hline 5 & Level 1 & Level 2 & Level 2 & 49.98849 & 2.454106 & 0.545894 & 0.472987650 & 15 \\
\hline 6 & Level 1 & Level 2 & Level 3 & 49.98987 & 2.099030 & 0.900970 & 0.557954552 & 12 \\
\hline 7 & Level 1 & Level 3 & Level 1 & 49.99084 & 4.722439 & 0.277561 & 0.601213257 & 9 \\
\hline 8 & Level 1 & Level 3 & Level 2 & 49.99411 & 4.454003 & 0.545997 & 0.700419933 & 6 \\
\hline 9 & Level 1 & Level 3 & Level 3 & 49.99971 & 4.099110 & 0.900890 & 0.811006325 & 3 \\
\hline 10 & Level 2 & Level 1 & Level 1 & 59.99118 & 0.722457 & 0.277543 & 0.137119017 & 26 \\
\hline 11 & Level 2 & Level 1 & Level 2 & 59.99311 & 0.454054 & 0.545946 & 0.231798941 & 23 \\
\hline 12 & Level 2 & Level 1 & Level 3 & 59.99428 & 0.099173 & 0.900827 & 0.388133717 & 20 \\
\hline 13 & Level 2 & Level 2 & Level 1 & 59.99375 & 2.722496 & 0.277504 & 0.428113113 & 17 \\
\hline 14 & Level 2 & Level 2 & Level 2 & 59.99482 & 2.454117 & 0.545883 & 0.487438923 & 14 \\
\hline 15 & Level 2 & Level 2 & Level 3 & 59.99558 & 2.099160 & 0.900840 & 0.571852066 & 11 \\
\hline 16 & Level 2 & Level 3 & Level 1 & 59.99626 & 4.722445 & 0.277555 & 0.611824026 & 8 \\
\hline 17 & Level 2 & Level 3 & Level 2 & 59.99713 & 4.454016 & 0.545984 & 0.722909267 & 5 \\
\hline 18 & Level 2 & Level 3 & Level 3 & 59.99802 & 4.099170 & 0.900830 & 0.862888293 & 2 \\
\hline 19 & Level 3 & Level 1 & Level 1 & 69.98970 & 0.722474 & 0.277526 & 0.189002483 & 25 \\
\hline 20 & Level 3 & Level 1 & Level 2 & 69.99228 & 0.454136 & 0.545864 & 0.261711699 & 22 \\
\hline 21 & Level 3 & Level 1 & Level 3 & 69.99401 & 0.099240 & 0.900760 & 0.398724250 & 19 \\
\hline 22 & Level 3 & Level 2 & Level 1 & 69.99537 & 2.722474 & 0.277526 & 0.442026416 & 16 \\
\hline 23 & Level 3 & Level 2 & Level 2 & 69.99685 & 2.454133 & 0.545867 & 0.502560160 & 13 \\
\hline 24 & Level 3 & Level 2 & Level 3 & 69.99735 & 2.099240 & 0.900760 & 0.582540580 & 10 \\
\hline 25 & Level 3 & Level 3 & Level 1 & 69.99872 & 4.722481 & 0.277519 & 0.618857155 & 7 \\
\hline 26 & Level 3 & Level 3 & Level 2 & 69.99941 & 4.454021 & 0.545979 & 0.734136576 & 4 \\
\hline 27 & Level 3 & Level 3 & Level 3 & 69.99948 & 4.099230 & 0.900770 & 0.889946149 & 1 \\
\hline
\end{tabular}

TABLE 6: Simulation experimental level.

\begin{tabular}{lcccc}
\hline $\begin{array}{l}\text { Control } \\
\text { factor }\end{array}$ & Level 1 & Level 2 & Level 3 & Unit \\
\hline $\begin{array}{l}\text { A: Inlet } \\
\text { temperature }\end{array}$ & 50 & 60 & 70 & ${ }^{\circ} \mathrm{C}$ \\
$\begin{array}{l}\text { B: Inlet } \\
\text { pressure }\end{array}$ & 1 & 3 & 5 & $\mathrm{bar}$ \\
C: Flow rate & 1 & 1.5 & 2 & $\mathrm{~m} / \mathrm{s}$ \\
\hline
\end{tabular}

The reason is that the semantic experiment obtains the equilibrium solution of the multiquality attributes (optimal relationship); therefore, there are differences. It is found in the Taguchi response table that the gap between flow rate Level 2 and Level 3 is only 0.0001, suggesting that the optimal semantic parameter combination of $\mathrm{A} 3 \mathrm{~B} 3 \mathrm{C} 2$ can result in good quality characteristics. This confirms that the triangular function definitions of the fuzzy theory can effectively obtain the optimal parameters.
TABLE 7: Three-quality simulation experimental response table.

\begin{tabular}{lccc}
\hline LEVEL & $\mathrm{A}$ & $\mathrm{B}$ & $\mathrm{C}$ \\
\hline 1 & 0.4744 & 0.2573 & 0.4926 \\
2 & 0.4936 & 0.4959 & 0.4943 \\
3 & 0.5133 & 0.7281 & 0.4944 \\
DELTA & 0.3890 & 0.4709 & 0.0018 \\
RANK & 2 & 1 & 3 \\
\hline
\end{tabular}

\section{Conclusions}

Through the triangular membership function and graded measurement, this study reduced the differences between fuzzy theory and practice; thus, it is conducive for application in multiquality PEMFC. By integrating fuzzy semantics and TOPSIS, good priority values and quality characteristics were obtained for practical use. In the future, the proposed procedure coupled with corresponding control parameters and quality considerations can be applied for different manufacturing methods to obtain the optimal parameter 
TABLE 8: Confirmation of the three qualities.

\begin{tabular}{|c|c|c|c|c|c|c|}
\hline $\begin{array}{l}\text { Three-quality } \\
\text { comparison }\end{array}$ & $\begin{array}{c}\text { Inlet } \\
\text { temperature }\end{array}$ & Inlet pressure & Flow rate & $\begin{array}{l}\text { Temperature } \\
\text { characteristic }\end{array}$ & $\begin{array}{c}\text { Pressure } \\
\text { characteristic }\end{array}$ & $\begin{array}{l}\text { Pressure drop } \\
\text { characteristic }\end{array}$ \\
\hline $\begin{array}{l}\text { Semantic } \\
\text { experiment }\end{array}$ & 3 & 3 & 2 & 69.99941 & 4.454021 & 0.545979 \\
\hline $\begin{array}{l}\text { Simulation } \\
\text { experiment }\end{array}$ & 3 & 3 & 3 & 69.99948 & 4.099230 & 0.900770 \\
\hline $\begin{array}{l}\text { Benchmark } \\
\text { parameters }\end{array}$ & 2 & 2 & 2 & 59.99800 & 2.454127 & 0.545873 \\
\hline
\end{tabular}

combination that reduces cost, while enhancing quality and industrial competitiveness.

\section{Conflict of Interests}

The authors declare that there is no conflict of interests regarding the publication of this paper.

\section{Acknowledgment}

Financial support for this work was provided by the National Science Council Taiwan, under the Contract no. NSC1022221-E-412-004.

\section{References}

[1] Y. M. Ferng and A. Su, "A three-dimensional full-cell CFD model used to investigate the effects of different flow channel designs on PEMFC performance," International Journal of Hydrogen Energy, vol. 32, no. 17, pp. 4466-4476, 2007.

[2] X. D. Wang, Y. Y. Duan, W. M. Yan, and X. F. Peng, "Local transport phenomena and cell performance of PEM fuel cells with various serpentine flow field designs," Journal of Power Sources, vol. 175, no. 1, pp. 397-407, 2008.

[3] X. Liu, H. Guo, F. Ye, and C. F. Ma, "Flow dynamic characteristics in flow field of proton exchange membrane fuel cells," International Journal of Hydrogen Energy, vol. 33, no. 3, pp. 1040-1051, 2008.

[4] D. Gillibrand, M. Sarwar, and C. T. Pierce, "The economic benefit of finish turning with coated carbide," Surface and Coatings Technology, vol. 86-87, no. 1, pp. 809-813, 1996.

[5] J. P. Davim and C. A. C. António, "Optimisation of cutting conditions in machining of aluminium matrix composites using a numerical and experimental model," Journal of Materials Processing Technology, vol. 112, no. 1, pp. 78-82, 2001.

[6] L. J. Chen, M. F. Hung, and M. S. Lee, "The influence of the flow field design to the performance of proton exchange membrane fuel cell," Journal of Technology, vol. 22, no. 1, pp. 71-76, 2007.

[7] W. C. Song, The study of fuzzy logic and group technology application to materials and manufacturing inference engine [M.S. dissertation], National Taiwan University of Science and Technology, 2006.

[8] L. C. Hsu, The study on the optimization of the parameters in plasma welding - the application of Taguchi method and artificial neural network [M.S. dissertation], I-Shou University, Taiwan, 1999.

[9] M. S. Phadke, Quality Engineering Using Robust Design, Prentice-Hall, 1989.
[10] K. H. Lu and C. C. Chiang, "The study on the fuzzy-based taguchi method on the manufacturing process of multiple quality characteristics-TFT metal coating as an example," Journal of Quality, vol. 17, no. 1, pp. 67-87, 2010.

[11] Z. W. Zhang, Solving the multi-quality characteristic problem of Taguchi method by using grey relational decision-making method-a case study of IC manufacturing [M.S. dissertation], Chung-Hua University, Taiwan, 1998.

[12] Y. L. Zhan, A study on the application of multi-attribute decisionmaking method in multi-quality characteristic optimization for dynamic systems [M.S. dissertation], National Chiao Tung University, Taiwan, 1999.

[13] C. H. Wang, Optimization of multiple responses and ordered categorical response using grey relational analysis [M.S. dissertation], National Chiao Tung University, Taiwan, 2000.

[14] G. F. Fang, The design of robust parameters of multi-quality characteristic products [M.S. dissertation], National Chiao Tung University, Taiwan, 2000. 


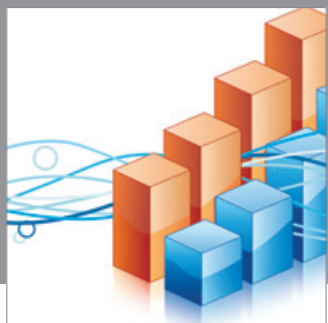

Advances in

Operations Research

mansans

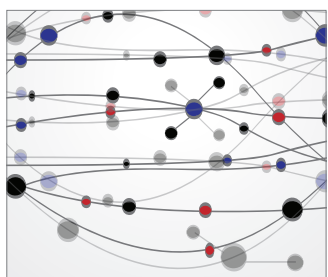

The Scientific World Journal
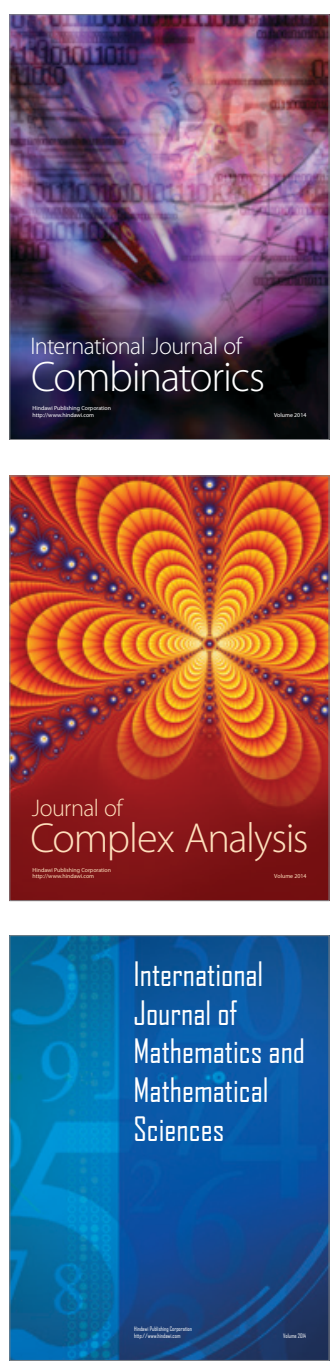
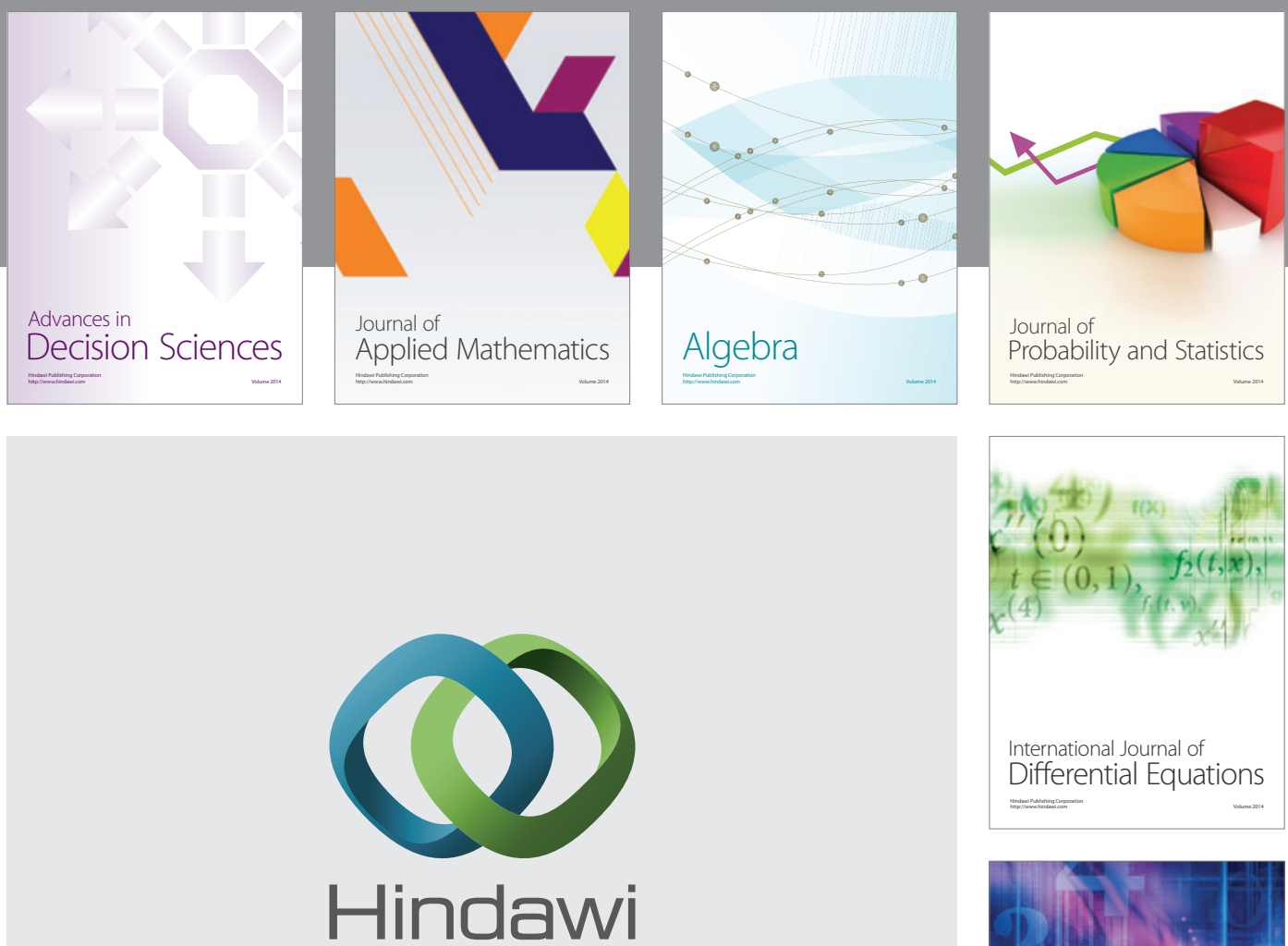

Submit your manuscripts at http://www.hindawi.com
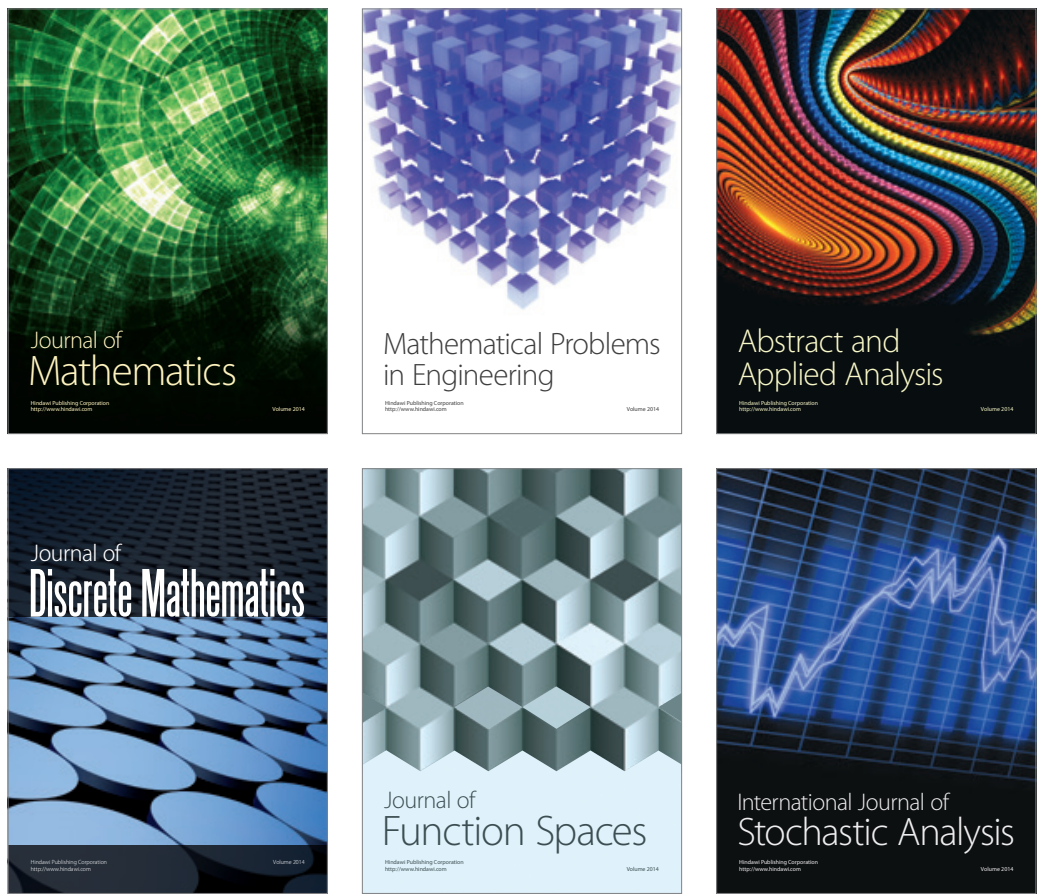

Journal of

Function Spaces

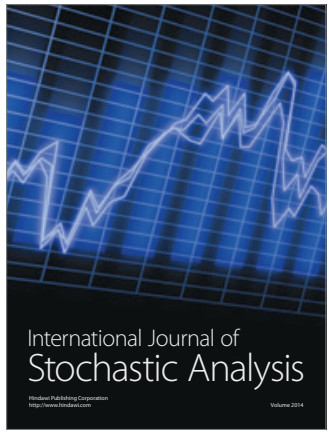

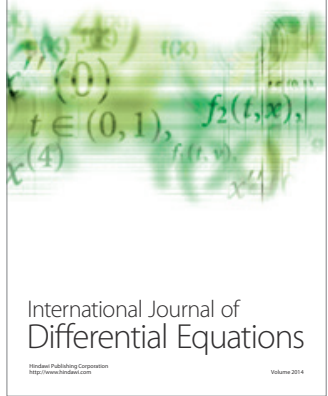
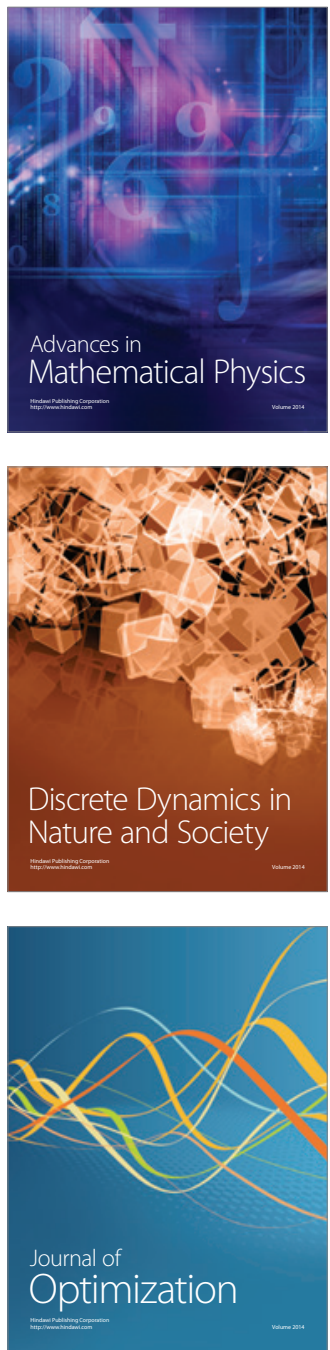